\title{
Left and right ventricular strain in the course of acute myocarditis: a cardiovascular magnetic resonance study
}

\section{Links- und rechtsventrikulärer Strain im Krankheitsverlauf der akuten Myokarditis: Eine kardiale MRT Studie}

Authors

Julian A. Luetkens, Pauline Petry, Daniel Kuetting, Darius Dabir, Frederic C. Schmeel, Rami Homsi, Hans H. Schild, Daniel Thomas

Affiliation

Radiology, University of Bonn, Germany

Key words

follow-up, myocarditis, cardiac magnetic resonance, myocardial strain analysis

received 28.12.2017

accepted 20.02.2018

Bibliography

DOI https://doi.org/10.1055/a-0585-0271

Published online: 2018

Fortschr Röntgenstr 2018; 190: 722-732

(c) Georg Thieme Verlag KG, Stuttgart · New York

ISSN 1438-9029

Correspondence

Dr. Julian A. Luetkens

Radiology, University of Bonn,

Sigmund-Freud-Str.25, 53127 Bonn, Germany

Tel.: + 49/2 28/28714414

Fax: $+49 / 228 / 28715960$

julian.luetkens@ukbonn.de

\section{ZUSAMMENFASSUNG}

Ziel Gegenstand der Studie war die Untersuchung im Rahmen einer Verlaufsbeobachtung der akuten Myokarditis dahingehend, ob Beeinträchtigungen in links- (LV) und rechtsventrikulären (RV) Strainparametern vorhanden sind. Darüber hinaus war beabsichtigt, die Strainparameter hinsichtlich ihrer Voraussagekraft für eine Funktionsnormalisierung in der Nachuntersuchung zu evaluieren.

Material und Methoden Es wurden 69 Patienten mit Myokarditis in der Akutphase (Baseline) und nach durchschnittlich 92,5 \pm 50,4 Tagen mittels kardialer Magnetresonanztomografie untersucht. Die „Lake Louise“ Kriterien (T2 Signalintensitätsratio, „early gadolinium enhancement ratio“ und „late gadolinium enhancement") und LV und RV myokardiale Strainparameter wurden ausgewertet. Eine logistische Regressionsanalyse wurde durchgeführt, um Prädiktoren für eine Funktionsnormalisierung in der Nachuntersuchung zu finden.
Ergebnisse Alle inflammatorischen Parameter verbesserten sich deutlich in der Nachuntersuchung $(P<0,001$ für alle Parameter). Entsprechend war auch die LV und RV Funktion in der Nachuntersuchung signifikant verbessert (LV Ejektionsfraktion: $53,5 \pm 12,7 \%$ vs. $61,3 \pm 9,5 \%$; $P<0,001$, RV Ejektionsfraktion: $54,1 \pm 10,0 \%$ vs. $59,4 \pm 6,3 \%$; $P<0,001)$. LV und RV Strainparameter (longitudinaler, zirkumferentieller und radialer Strain) verbesserten sich ebenfalls in der Nachuntersuchung signifikant im Vergleich zur initialen Untersuchung $(P<0,05$ für alle Parameter). Der initiale LV globale systolische longitudinale Strain war der einzige Parameter in der multivariaten Regressionsanalyse, der unabhängig eine Funktionsverbesserung in der Nachuntersuchung voraussagen konnte (OR: 0,303; $P=0,007)$. Schlussfolgerung Pathologische Veränderungen in LV und RV Strainparameter lassen sich in der Akutphase der Myokarditis häufig beobachten. Im Laufe der Erkrankung erholen sich diese Funktionseinschränkungen häufig wieder. Die zusätzliche Bestimmung des initialen LV globalen systolischen longitudinalen Strains könnte zudem hilfreich sein, eine Funktionsnormalisierung im Laufe der Erkrankung vorauszusagen.

\section{Kernaussagen}

- Beeinträchtigungen des myokardialen Strains bei Myokarditis erholen sich meist im Verlauf.

- Eine RV Dysfunktion kann in der Akutphase häufig beobachtet werden.

- Der LV longitudinale Strain kann eine Funktionsnormalisierung in der Verlaufsuntersuchung voraussagen.

\section{ABSTRACT}

Purpose To investigate the degree of impairment in left (LV) and right ventricular (RV) myocardial strain parameters over the course of acute myocarditis and to evaluate its value for the prediction of functional recovery upon follow-up.

Materials and Methods 69 patients with acute myocarditis underwent cardiac magnetic resonance imaging during the acute stage (baseline) and after a mean $92.5 \pm 50.4$ days follow-up. Standard "Lake Louise" criteria (T2 signal intensity ratio, early gadolinium enhancement ratio and late gadolinium enhancement) and feature tracking derived LV and RV strain parameters were assessed. Logistic regression analysis was used to find predictors of functional recovery upon follow-up. 
Results All inflammatory parameters showed a considerable decrease over the course of the disease $(P<0.001$ for all parameters). LV and RV function significantly improved on follow-up CMR (LV ejection fraction: $53.5 \pm 12.7 \%$ vs. 61.3 $\pm 9.5 \%$; $P<0.001$, RV ejection fraction: $54.1 \pm 10.0 \%$ vs. 59.4 $\pm 6.3 \%$; $<0.001$ ). LV and RV myocardial strain (longitudinal, circumferential and radial strain) significantly improved from baseline to follow-up ( $\mathrm{P}<0.05$ for all parameters). On multivariate analysis, LV global peak systolic longitudinal strain (OR: 0.303; $P=0.007$ ) was the only independent predictor of functional recovery upon follow-up.

Conclusion Alterations in LV and RV functional strain parameters occur frequently during the acute stage of myocarditis. During the course of the disease, a significant improvement in LV and RV strain parameters can be observed. It further appears that initial LV longitudinal strain may serve as a new parameter for the prediction of functional recovery upon follow-up.

\section{Key Points}

- Myocardial strain parameters significantly improve during the course of acute myocarditis.

- RV dysfunction can frequently be observed during the acute stage of myocarditis.

- LV longitudinal strain can independently predict functional recovery upon follow-up.

\section{Citation Format}

- Luetkens JA, Petry P, Kuetting D et al. Left and right ventricular strain in the course of acute myocarditis: a cardiovascular magnetic resonance study. Fortschr Röntgenstr 2018; 190: 722-732

\section{Introduction}

Myocarditis accounts for up to $20 \%$ of sudden unexpected deaths in young adults and has been identified as a substantive cause of cardiac mortality and morbidity [1]. The course of myocarditis is subject to substantial individual variations and the clinical management remains difficult [2]. Healed myocarditis can often be indirectly assumed in the absence of persisting symptoms if myocardial function and biomarkers have normalized [3]. However, in some cases, dilated cardiomyopathy may result from persistent myocardial inflammation [4]. Although confirming the presence of myocarditis is primarily a histopathological diagnosis [5], cardiac magnetic resonance (CMR) is more and more considered to be an alternative option for the diagnostic evaluation of patients presenting with symptoms of acute myocarditis $[6,7]$. In the follow-up of acute myocarditis, CMR can identify patients with ongoing inflammation of the myocardium who ultimately require an additional endomyocardial biopsy for an optimized therapeutic regime [8]. Also, CMR can provide important information regarding the prognosis of patients suffering from myocarditis. The initial presence of myocardial oedema has been described to strongly predict left ventricular (LV) functional recovery [9], whereas the presence of non-ischemic necrosis on late gadolinium enhancement (LGE) imaging is regarded as an independent predictor of all-cause and cardiac mortality [10]. Another newer CMR technique, which also adds important information to multiparametric myocarditis CMR, is the determination of myocardial strain and deformation parameters using a feature tracking technique $[6,11]$. Myocardial strain parameters are typically reduced during early-stage pathogenesis $[12,13]$, however, the predictive value of strain parameters for the recovery of LV function is not known. In addition, the predictive value of right ventricular (RV) functional parameters for outcome prediction has only been addressed by a few studies [14], and little is known about RV deformation analysis over the course of acute myocarditis. The aim of this study was to evaluate: (1) whether RV dysfunction can be observed during the course of acute myocarditis, and (2) the predictive value of several CMR parameters including myocardial strain analysis for the prediction of functional recovery upon follow-up.

\section{Methods}

Ethics commission approval was obtained for this retrospective study. The requirement to obtain written informed consent was waived. This study included the datasets of 69 patients with clinically suspected myocarditis who underwent an initial CMR after admission and a follow-up CMR between June 2008 and April 2016 at our department. Acute myocarditis was diagnosed based on diagnostic criteria for clinically suspected myocarditis as recommended of the European Society of Cardiology Working Group on myocardial and pericardial diseases [5, 6]. All patients had the diagnosis of acute myocarditis at hospital discharge. Patients with coronary artery disease, previous myocarditis or myocardial infarction were not included in this study.

\section{CMR scans}

CMR investigations were conducted on clinical whole body CMR scanners (Intera 1.5 Tesla, Ingenia 1.5 Tesla or Ingenia 3 Tesla, Philips Healthcare, Best, The Netherlands). ECG-gated steadystate free precession cine images were acquired for functional measurements and strain analysis. Cine images were obtained in short axis, 4-chamber and 2-chamber views. Short axis views of T2-weighted short-tau inversion-recovery (STIR) sequences were acquired in order to visualize myocardial oedema and to calculate $\mathrm{T} 2$ signal intensity (SI) ratio. For the assessment of myocardial hyperaemia (early gadolinium enhancement), axial fast spin echo T1-weighted images were acquired in free-breathing directly before and after contrast administration [15]. For LGE imaging, segmented inversion-recovery gradient-echo sequences were acquired in short axis, 4-chamber and 2-chamber views. Contrast was given as a bolus of $0.2 \mathrm{mmol} / \mathrm{kg}$ of body weight of gadobutrol (Gadovist, Bayer Healthcare, Leverkusen, Germany). Typical sequence parameters are summarized in $>$ Table S1 (online-only supplement).

\section{Analysis of CMR images}

Analysis of CMR images and data was performed by two blinded, experienced radiologists. Image analysis was conducted using a 
- Table 1 Clinical parameters at baseline.

- Tab. 1 Klinische Parameter in der Akutphase (Baseline).

\begin{tabular}{|l|l|}
\hline Parameter & Baseline (n=69) \\
\hline Age $(\mathrm{y})$ & $41.8 \pm 18.8$ \\
\hline Male patients & $52(75 \%)$ \\
\hline Body mass index $\left(\mathrm{kg} / \mathrm{m}^{2}\right)$ & $27.2 \pm 6.0$ \\
\hline Troponin I $(\mathrm{ng} / \mathrm{mL})$ & $14.8 \pm 66.3$ \\
\hline CK-MB $(\mu \mathrm{g} / \mathrm{l})$ & $21.3 \pm 34.2$ \\
\hline Leukocytes $\left(10^{3} / \mu \mathrm{L}\right)$ & $18.9 \pm 10.9$ \\
\hline C-reactive protein $(\mathrm{mg} / \mathrm{L})$ & $60.4 \pm 61.2$ \\
\hline Creatinine $(\mathrm{mg} / \mathrm{dl})$ & $1.00 \pm 0.33$ \\
\hline $\begin{array}{l}\text { Continuous variables are given as mean } \pm \text { standard deviation. Dichot- } \\
\text { omous variables are given as absolute frequency with percentages in } \\
\text { parentheses. }\end{array}$ \\
\hline
\end{tabular}

dedicated CMR software (IntelliSpace Portal 9.0, Philips Medical Systems, Best, The Netherlands). LV and RV function was analysed based on the recommendations of the Society for Cardiovascular Magnetic Resonance (SCMR) [16]. LV functional recovery was defined as an ejection fraction on follow-up of $\geq 55 \%$. The presence of segmental myocardial oedema on T2 STIR images was visually evaluated by consensus agreement of two radiologists. The presence of inflammatory lesions in a non-ischemic distribution on LGE were also visually assessed. In addition, a semi-quantitative analysis of LGE images was performed. The endocardial and the epicardial contours of short axis LGE images were contoured manually and the enhanced volume percentage was calculated using the full width at half maximum (FWHM) technique [16]. T2 SI ratio as a marker of diffuse myocardial oedema and early gadolinium enhancement ratio (EGEr) as a marker of inflammation-induced hyperaemia were calculated as recommended for the assessment of the "Lake Louise" criteria [15].

\section{Analysis of left and right ventricular myocardial strain}

CMR feature tracking strain measurements were derived from cine images using a dedicated software (Image-Arena 4.6, TomTec Imaging Systems, Unterschleissheim, Germany). Short axis cine images were used to derive circumferential and radial strain and strain rate measures of the left and right ventricle. Basal, midventricular, and apical short axis images were analysed for circumferential and radial strain assessment. The 4-chamber cine images were used to obtain LV and RV longitudinal strain and strain rate measures. Global systolic radial, circumferential and longitudinal strain and strain rate values were calculated from peak segmental data. Measurements were performed as previously described [13].

\section{Statistics}

Prism 7 (GraphPad Software, La Jolla, CA, USA) and SPSS Statistics 23 (IBM, Armonk, NY, USA) were used for statistical analysis. Continuous variables are presented as mean \pm standard deviation.

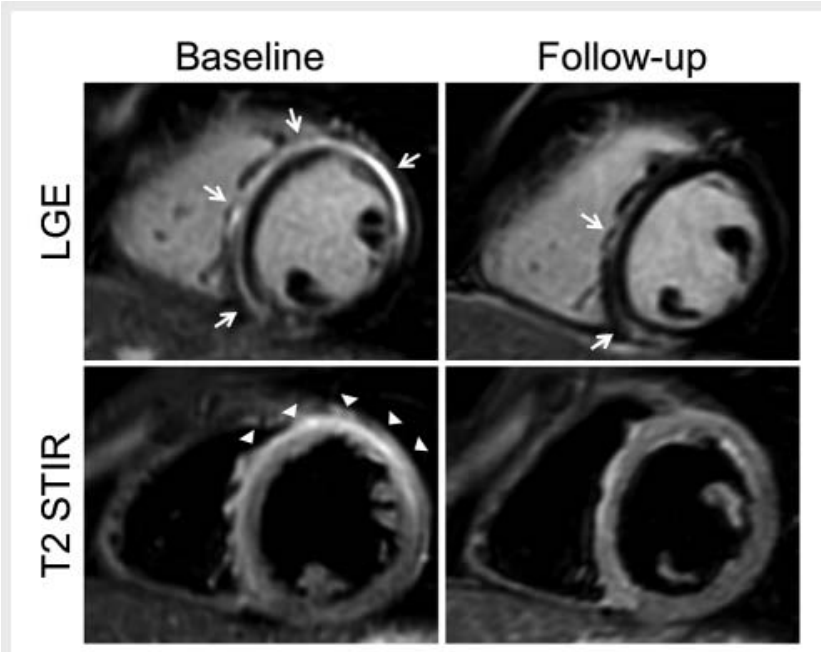

- Fig. 1 Baseline and follow-up late gadolinium enhancement (LGE) and T2 STIR images in a 20-year-old male with acute myocarditis. Images show inflammatory, non-ischemic lesions in the midventricular segment of left ventricle. Myocardial oedema resolved from baseline (white arrowheads) to follow-up. LGE was persistently visible at follow-up (white arrows).

- Abb. 1 Baseline-Untersuchung und Nachuntersuchung bei einem 20-jährigen Patienten mit akuter Myokarditis. Es sind entzündliche, nicht-ischämische Läsionen zu erkennen. In der T2 STIR Bildgebung hat sich das Myokardödem in der Nachuntersuchung vollständig aufgelöst (weiße Pfeilspitzen). Das „late gadolinium enhancement" (LGE) ist in Nachuntersuchung immer noch nachweisbar (weiße Pfeile).

A testing for normal distribution was performed for continuous variables. Dichotomous variables are presented as absolute frequency. For inter-individual group comparisons, the independent 2-sample Student t test was applied. For intra-individual group comparisons, the paired Student $t$ test was used. Inter-individual comparisons of dichotomous variables were performed using the $x^{2}$ test (cell count $>5$ ) or the Fisher exact test (cell count $\leq 5$ ) for. For intra-individual comparisons, the McNemar's test was used. For correlation analysis, the Spearman's rank correlation coefficient was performed. Significant independent predictors of LV functional recover were analysed by univariate and subsequent multivariate binary logistic regression analysis. Results are displayed as odds ratio (OR) with $95 \%$ confidence interval $(\mathrm{Cl})$. Diagnostic performance of parameters for the prediction of functional recovery was analysed by plotting receiver operation characteristics (ROCs). A P value of $<0.05$ was considered to be statistically significant.

\section{Results}

\section{General results}

The datasets of 69 patients were analysed in this study. Mean age of the study population was $41.8 \pm 18.8$ years (range: $18-76$ ). Clinical parameters at baseline are presented in $>$ Table 1. After admission to the hospital, initial CMR was performed after 5.6 
- Table 2 CMR parameters of patients at baseline and follow-up.

- Tab.2 Parameter der kardialen MRT in der initialen Untersuchung (Baseline) und in der Nachuntersuchung.

\begin{tabular}{|c|c|c|c|}
\hline Parameter & Baseline $(n=69)$ & Follow-Up $(n=69)$ & $P$ value \\
\hline LV ejection fraction (\%) & $53.5 \pm 12.7$ & $61.3 \pm 9.5$ & $<0.001$ \\
\hline LV enddiastolic volume (ml) & $167.4 \pm 53.0$ & $159.0 \pm 48.7$ & 0.002 \\
\hline RV ejection fraction (\%) & $54.1 \pm 10.0$ & $59.4 \pm 6.3$ & $<0.001$ \\
\hline RV enddiastolic volume (ml) & $134.9 \pm 47.9$ & $137.0 \pm 38.3$ & 0.488 \\
\hline T2 SI ratio & $1.9 \pm 0.4$ & $1.7 \pm 0.3$ & $<0.001$ \\
\hline Early gadolinium enhancement ratio & $4.5 \pm 4.1$ & $2.5 \pm 1.2$ & $<0.001$ \\
\hline Visible regional myocardial oedema & $53(77 \%)$ & $6(9 \%)$ & $<0.001$ \\
\hline Visible late gadolinium enhancement & $61(88 \%)$ & $45(66 \%)$ & $<0.001$ \\
\hline Late gadolinium enhancement (\%) & $7.1 \pm 5.0$ & $6.1 \pm 4.7$ & 0.002 \\
\hline Positive “Lake Louise” criteria & $57(83 \%)$ & $18(26 \%)$ & $<0.001$ \\
\hline LV longitudinal strain (\%) & $-18.6 \pm 5.0$ & $-20.9 \pm 3.9$ & $<0.001$ \\
\hline LV longitudinal strain rate (1/s) & $-1.6 \pm 0.4$ & $-1.5 \pm 0.4$ & 0.815 \\
\hline LV circumferential strain (\%) & $-20.0 \pm 6.0$ & $-23.1 \pm 4.8$ & $<0.001$ \\
\hline LV circumferential strain rate $(1 / \mathrm{s})$ & $-1.7 \pm 0.5$ & $-1.7 \pm 0.5$ & 0.353 \\
\hline LV radial strain (\%) & $33.9 \pm 12.7$ & $38.0 \pm 11.8$ & 0.030 \\
\hline LV radial strain rate $(1 / \mathrm{s})$ & $2.1 \pm 0.7$ & $2.2 \pm 1.1$ & 0.663 \\
\hline RV longitudinal strain (\%) & $-22.8 \pm 6.0$ & $-24.6 \pm 4.8$ & 0.010 \\
\hline RV longitudinal strain rate $(1 / \mathrm{s})$ & $-1.9 \pm 0.6$ & $-1.9 \pm 0.9$ & 0.889 \\
\hline RV circumferential strain (\%) & $-13.6 \pm 3.8$ & $-14.9 \pm 3.0$ & 0.012 \\
\hline RV circumferential strain rate $(1 / \mathrm{s})$ & $-1.3 \pm 0.4$ & $-1.2 \pm 0.4$ & 0.070 \\
\hline RV radial strain (\%) & $19.5 \pm 7.0$ & $21.2 \pm 6.6$ & 0.052 \\
\hline RV radial strain rate $(1 / \mathrm{s})$ & $1.5 \pm 0.6$ & $1.4 \pm 0.4$ & 0.133 \\
\hline
\end{tabular}

\pm 6.5 days. Patients with myocarditis were followed up $92.5 \pm 50.4$ days after initial CMR. During the study period, no deaths or heart transplantations occurred.

\section{CMR results}

All inflammatory CMR parameters showed a significant decrease from baseline compared to follow-up (see $>$ Table 2): T2 SI ratio $(1.9 \pm 0.4$ vs. $1.7 \pm 0.3 ; \mathrm{P}<0.001)$; $\operatorname{EGEr}(4.5 \pm 4.1$ vs. $2.5 \pm 1.2$; $P<0.001)$. Quantitative LGE also significantly declined over time (7.1 $\pm 5.0 \%$ vs. $6.1 \pm 4.7 \% ; P=0.002$ ) (see > Fig. 1 ). On visual analysis, LGE was still present in $65 \%$ (45/69) of all patients on follow-up. LV ejection fraction showed a significant improvement from baseline to follow-up $(53.5 \pm 12.7$ vs. $61.3 \pm 9.5$; $\mathrm{P}<0.001)$. On baseline, $24 /$ 69 (34.9\%) patients presented with a reduced RV function (RV ejection fraction $<52 \%$ ). Furthermore, baseline RV function was significantly correlated with baseline LV ejection fraction $(r=0.668$; $P<0.001)$. Also, RV global peak longitudinal strain was significantly correlated with RV function ( $r=-0.411 ; P=0.001)$ and LV longitudinal strain $(r=0.558 ; P<0.001)$ (see $>$ Fig. 2). Over the course of the disease, $R V$ ejection fraction significantly improved from baseline to follow-up (54.1 \pm 10.0 vs. 59.4 \pm 6.3 ; $\mathrm{P}<0.001)$. Except RV global peak systolic radial strain, all myocardial LV and RV strain parameters (longitudinal strain, circumferential strain and radial strain) significantly improved from baseline to follow-up ( $P<0.05$ for all parameters) (see - Fig. 3, 4). 30/69 (43\%) of all patients presented with an impaired LV ejection fraction at baseline. Patients with a reduced baseline LV ejection fraction also had reduced RV ejection fraction (54.1 \pm 10.0 vs. $59.4 \pm 6.3 ; \mathrm{P}<0.001$ ) and reduced LV and RV strain parameters ( $P<0.05$ for all parameters) compared to patients with preserved LV ejection fraction at baseline (see $>$ Table 3). Interestingly, no differences were observed in visible myocardial oedema (77\% vs. $85 \% ; \mathrm{P}=0.701$ ) and visible late gadolinium enhancement ( $83 \%$ vs. $92 \% ; P=0.219$ ) between both groups. $18 / 69$ (26\%) of all patients had positive "Lake Louise" criteria at follow-up, as a CMR sign of ongoing myocarditis.

Patients with positive "Lake Louise" criteria on follow-up had a comparable LV and RV function compared to without positive "Lake Louise" criteria (LV ejection fraction: $61.9 \pm 8.0$ vs. 61.2 $\pm 10.0 ; P=0.758$; RV ejection fraction: $59.6 \pm 7.4$ vs. $59.4 \pm 5.9$; 

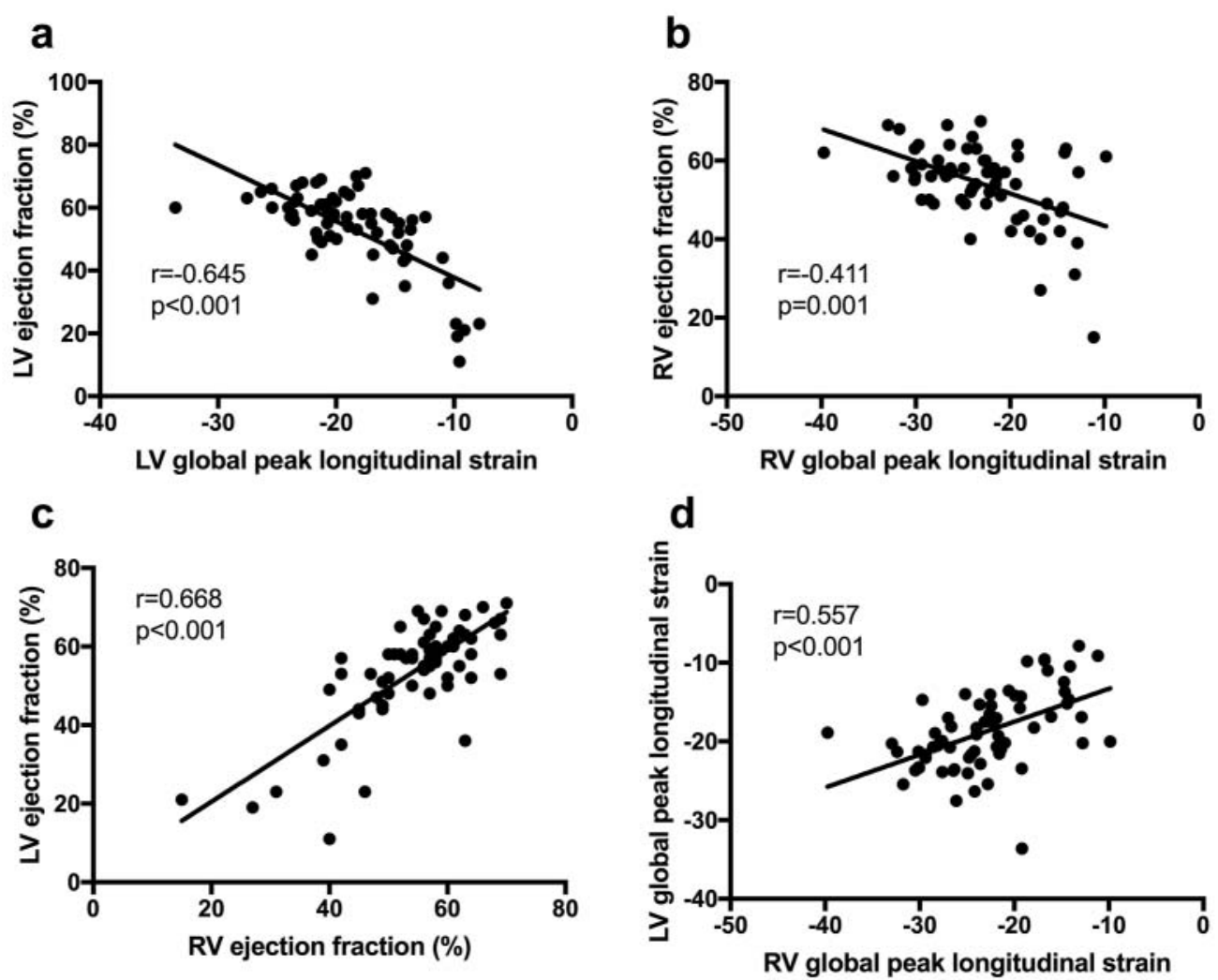

- Fig. 2 Scatter plots showing correlations between left ventricular (LV) ejection fraction and LV global peak longitudinal strain a, right ventricular (RV) ejection fraction and RV global peak longitudinal strain $\mathbf{b}, \mathrm{LV}$ ejection fraction and RV ejection fraction $\mathbf{c}$, and LV global peak longitudinal strain and RV global peak longitudinal strain $\mathbf{d}$.

- Abb.2 Die Streudiagramme zeigen Korrelationen zwischen linksventrikulärer (LV) Ejektionsfraktion und LV longitudinalem Strain a, rechtsventrikulärer (RV) Ejektionsfraktion und RV longitudinalem Strain b, LV Ejektionsfraktion und RV Ejektionsfraktion c, und LV longitudinalem Strain und RV longitudinalem Strain d.

$P=0.918)$. Also, no differences were observed in myocardial strain parameters ( $P>0.05$ for all parameters).

\section{Impact of different CMR parameters for the prediction functional recovery}

$59 / 69$ (85.5\%) of all patients had a normal LV myocardial function (LV ejection fraction $>55 \%$ ) upon follow-up. In the univariate logistic regression analysis, LV (OR: 1.232 (Cl: $1.088-1.395)$; $\mathrm{P}=0.001)$ and $\mathrm{RV}$ ejection fraction (OR: 1.190 (Cl: $1.064-1.331)$; $\mathrm{P}=0.002)$, visible myocardial oedema (5.778 (Cl: $1.219-27.388)$; $\mathrm{P}=0.027)$ and LV and RV global peak strain parameters $(\mathrm{P}<0.05$ for all parameters) showed a predictive value for a functional recovery upon follow-up. In the multivariate model, LV global peak systolic longitudinal strain (OR: 0.303 (Cl: $0.128-0.718)$; $\mathrm{P}=0.007$ ) was the only independent predictor of functional recovery upon follow-up. The results of the univariate and multivariate logistic regression analysis are summarized in $>$ Table 4. Using a cut-off of $<-16.9 \%$, LV global peak systolic longitudinal strain had a sensitivity of $90.0 \%$ and a specificity of $75.4 \%$ for the prediction of functional recovery upon follow-up.
Also in patients with initially reduced LV ejection fraction, LV global peak systolic longitudinal strain remained the only significant multivariate predictor of functional recovery upon follow-up (OR: 0.296 (Cl $0.102-0.858) ; P=0.025)$ (see $>$ Table 5). In these patients, LV global peak systolic longitudinal strain had a sensitivity of $85.7 \%$ and a specificity of $95.5 \%$ (cut-off: <-12.3\%) for the prediction of functional recovery upon follow-up (see $>$ Fig. 5).

\section{Discussion}

In this retrospective follow-up study in patients with acute myocarditis, we described the changes of various CMR parameters including LV and RV myocardial strain over the course of the disease and evaluated their value for the prediction of functional recovery. The main findings of our study are that (1) RV dysfunction may frequently be observed during the acute stage of myocarditis, (2) LV longitudinal strain was the only independent predictor of functional recovery upon follow-up. 


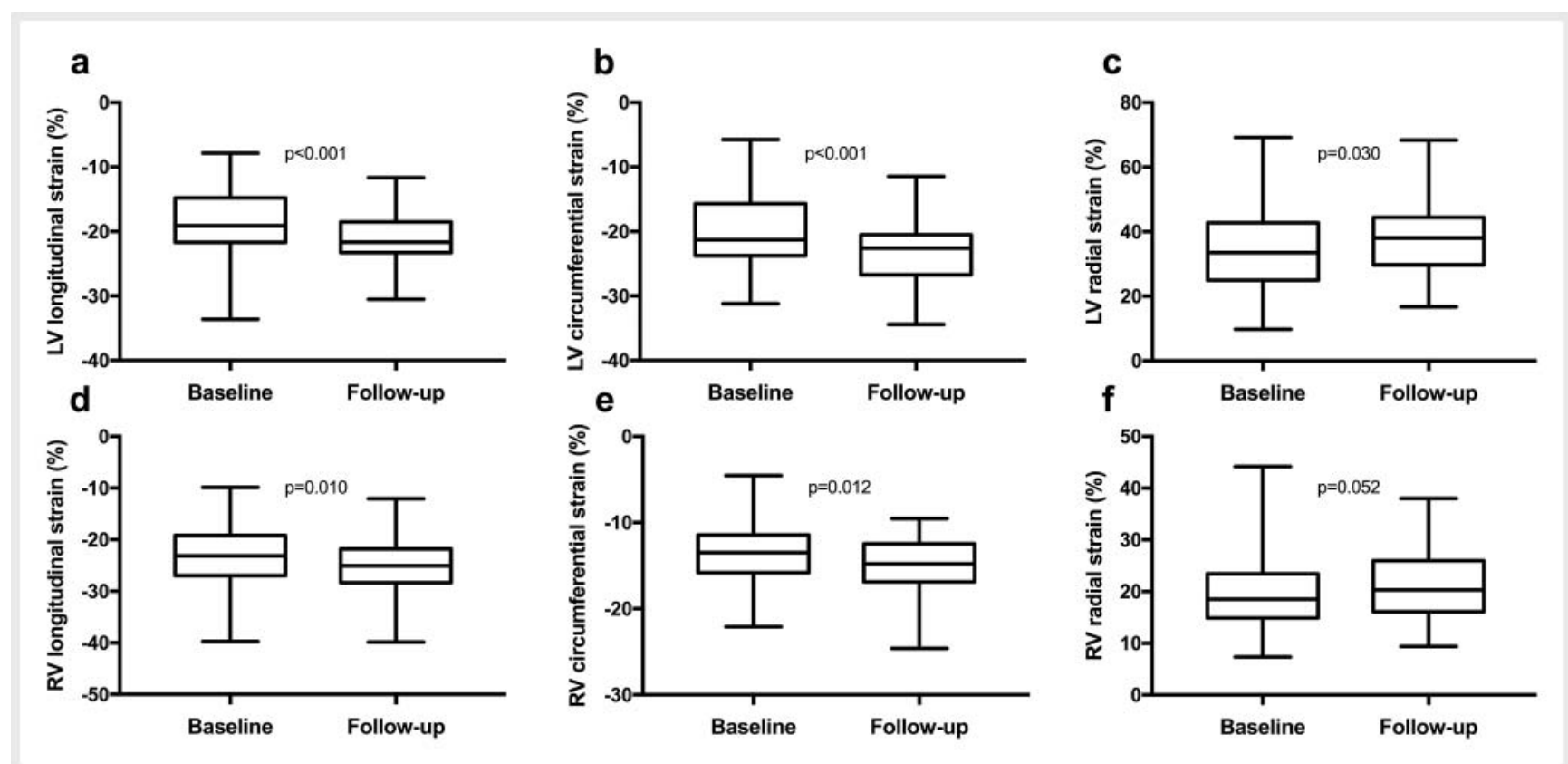

- Fig. 3 Box-whisker plots of different left (LV) and right ventricular (RV) myocardial strain parameters between baseline and follow-up. The data points are sorted from the maximum to the minimum. The boxes represent the data between the first and third quartiles. The median is represented by the horizontal line in the middle of the boxes. Differences are shown for a LV global peak systolic longitudinal strain, $\mathbf{b}$ LV global peak systolic circumferential strain, c LV global peak systolic radial strain, d RV global peak systolic longitudinal strain, e RV global peak systolic circumferential strain, and $\mathbf{f} R V$ global peak systolic radial strain.

- Abb. 3 Die Box-Whisker-Plots zeigen die Ergebnisse unterschiedlicher links- (LV) und rechtsventrikulärer (RV) Strainparameter in der Baseline und in der Nachuntersuchung. a LV longitudinaler Strain, b LV zirumferentieller Strain, c LV radialer Strain, d RV longitudinaler Strain, e RV zirkumferentieller Strain, und $\mathbf{f} R V$ radialer Strain.

\section{“Lake Louise” criteria}

CMR is increasingly used for the diagnosis, evaluation, and followup of patients suffering from myocarditis [7, 8, 13]. Using standard "Lake Louise" criteria, CMR can reliably detect inflammatory myocardial alteration in the acute setting. In follow-up investigations, CMR can monitor inflammatory activity of the heart muscle and may help to identify patients with persistent signs of myocardial inflammation, who might require a subsequent endomyocardial biopsy for a more specific therapy [8]. Several CMR studies have described the temporal evolution of the "Lake Louise" criteria $[8,9]$. In this regard, EGEr is a CMR parameter of active inflammation, which is mostly elevated in the acute stage of the disease. As was observed in this study, a recovery of EGEr is seen fairly quickly in most of the cases $[8,17,18]$.

Comparable to myocardial hyperaemia, myocardial oedema also represents a sign of active myocardial inflammation [19]. During the course of myocarditis, myocardial oedema is mainly visible in the acute phase and often dissolves quickly [20]. In a recently published study, myocardial oedema was only visible in $4 \%$ of all patients after a 16 weeks' follow-up [8]. In this study, myocardial oedema was visible in $9 \%$ of all patients after a 90 days' follow-up. Vermes et al. described the presence of myocardial oedema to be associated with LV function recovery following acute myocarditis [9]. In this study, regional myocardial oedema could also predict functional recovery, but only on the univariate analysis. In acute myocarditis, myocardial oedema should be regarded as a marker of reversibly injured myocardium as an improvement of global and regional myocardial function closely follows the regression of myocardial oedema [9, 21].

In the acute setting, LGE is a CMR marker of myocardial necrosis and represents irreversible myocardial injury [8, 22]. During the healing process, this necrotic tissue is replaced by a fibrotic scar [9, 22]. This persistence of scar tissue leads to relatively high percentage of patients with positive LGE on follow-up investigations, even in patients without any signs of ongoing inflammation (e. g. myocardial oedema) $[8,23]$. Accordingly, $66 \%$ of all patients had a persistence of LGE on follow-up in our study. Although positive LGE is considered to be a good predictor of sudden cardiac death and all-cause mortality in myocarditis, it surprisingly does not play a role in the prediction of incomplete recovery [10], as also shown in our study. The association between LGE and sudden cardiac death might be explained by the essential role of myocardial fibrotic remodelling as a substrate for cardiac arrhythmia [24], which seems to be independent of LV functional improvement.

\section{Ventricular function and strain}

Although myocardial inflammation in acute myocarditis is assumed to involve the left and the right ventricle, only very few studies investigated right ventricular function in the course of the disease. A follow-up study in patients with biopsy-proven myocarditis found initial abnormal right ventricular function to be a good predictor of poor outcome [14]. In our study, global RV function 


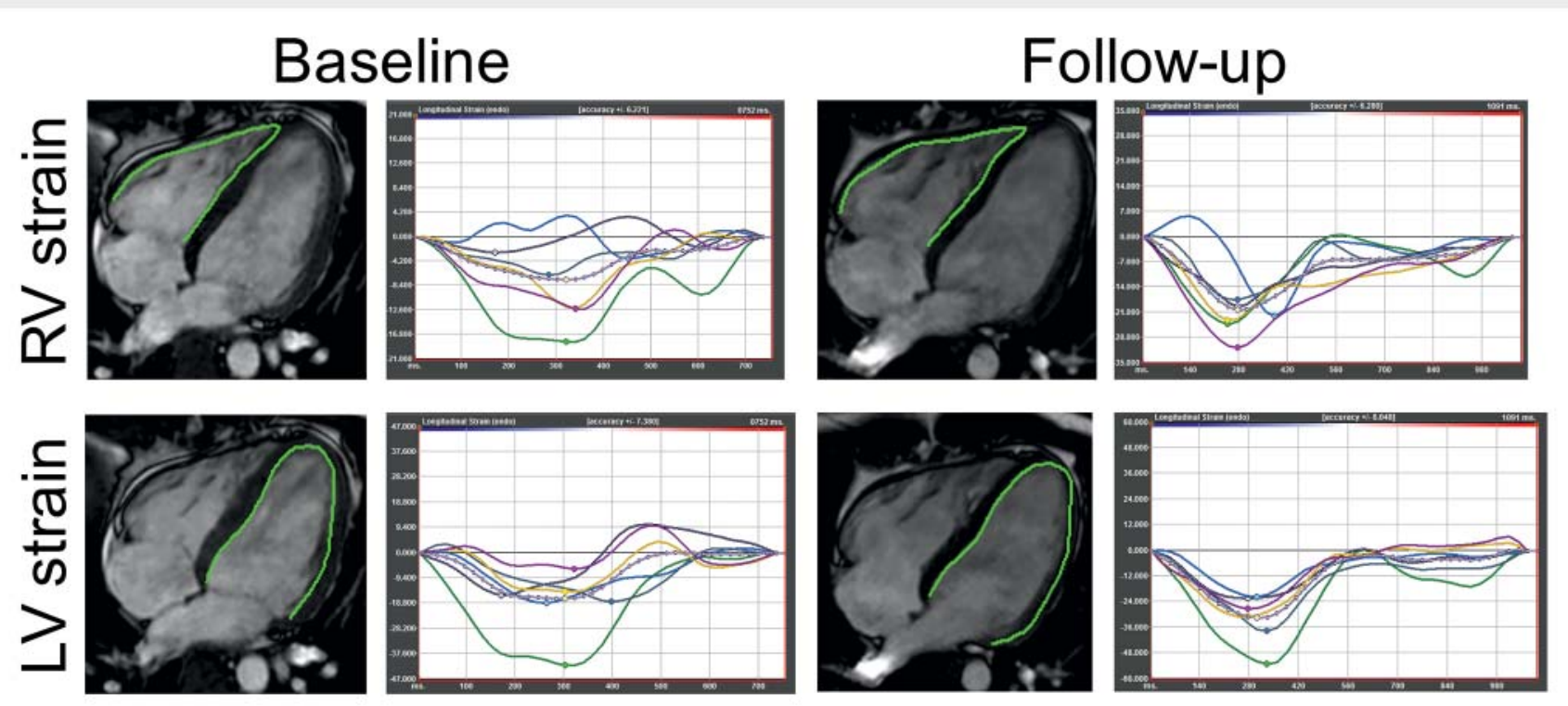

- Fig. 4 Left (LV) and right ventricular (RV) longitudinal strain curves at baseline and follow-up in a 26-year-old male with acute myocarditis. The color-coded curves given in the strain graph represent the longitudinal strain of different segments versus time. The dotted represents the average strain of all segments. The LV and RV longitudinal strain is reduced at baseline. At follow-up, LV and RV longitudinal strain values increase and the strain curves align themselves more uniformly.

- Abb. 4 Links- (LV) und rechtsventrikuläre (RV), longitudinale Strainkurven in der Akutphase (Baseline) und in der Nachuntersuchung bei einem 24-jährigem Patienten mit akuter Myokarditis. Die farbigen Strainkurven repräsentieren unterschiedliche segmentale Strainwerte während des Herzzyklus. Die gepunktete Linie repräsentiert den durchschnittlichen Strain aller Segmente. In der Baseline-Untersuchung ist der LV und RV longitudinale Strain reduziert. In der Nachuntersuchung normalisieren sich die Strainwerte und die Kurven gleichen sich wieder mehr an.

was distinctly decreased at baseline compared to follow-up. Comparably, RV strain indices were also markedly reduced. We also found positive correlations between baseline RV functional parameters and LV functional parameters. Therefore, our results indicate that right ventricular involvement in acute myocarditis may be a frequent finding, which is associated with left ventricular functional impairment. This thesis is supported by the fact that histopathological diagnosis of myocarditis is often obtained from right ventricular biopsy specimens indicating a not insubstantial load of inflammatory activity in the right ventricle [25].

Myocardial strain analysis can detect regional and global myocardial dysfunction in acute myocarditis and may serve as a new diagnostic CMR target $[13,26]$. Several case-control studies have described myocardial strain indices to be decreased in acute myocarditis, even in patients with preserved ejection fraction $[12,13]$. In our follow-up study on patients with myocarditis, we could show that myocardial strain indices significantly improved from baseline to follow-up. Myocardial strain analysis might therefore be suitable for intraindividual disease monitoring, when a normalisation of myocardial strain parameters should be expected upon follow-up. Interestingly, we found LV global systolic longitudinal strain to be the only predictor of full functional recovery upon follow-up on multivariate analysis. Despite the established role of LV ejection fraction for outcome prediction, several other studies indicated an incremental value of LV longitudinal strain for risk stratification in patients with various cardiac disease (e. g. in dilated cardiomyopathy or acute myocardial infarction) $[27,28]$. The prognostic value of global longitudinal strain for predicting major adverse cardiac events is regarded to be superior compared to standard ejection fraction alone [27]. Arenja et al. reported longitudinal strain to be an independent parameter for outcome and offers incremental information beyond LV ejection fraction and the presence of myocardial fibrosis in patients with dilated cardiomyopathy [28]. This superiority of longitudinal strain was also shown in an analysis of the right ventricle [29]. Using the feature tracking technique, longitudinal strain has been reported to be the only independent prognostic parameter in patients with dilated cardiomyopathy, surpassing the prognostic value of radial and circumferential strain [30]. Also, previous feature tracking CMR studies reported global longitudinal strain to offer a more robust intra- and inter-observer variability compared to other strain parameters (e. g. global radial strain values) [31, 32]. Furthermore, feature tracking global longitudinal strain has been reported to offer a very low inter-study reproducibility [31].

In patients with acute myocarditis, only a few studies evaluated the prognostic value of strain parameters: An echocardiographic study described longitudinal and circumferential strain to be significant predictors of cardiac outcome following acute myocarditis [33]. Recently, Lee et al. reported that radial long-axis strain can predict major adverse cardiovascular events and incomplete LV functional recovery [26].

In summary, our results indicate an increasing evidence that myocardial strain analysis can also provide additional information regarding outcome prediction in patients with acute myocarditis. 
- Table 3 CMR findings at baseline of patients with impaired and preserved ejection fraction.

- Tab.3 Ergebnisse der kardialen MRT in der Akutphase (Baseline) bei Patienten mit eingeschränkter und erhaltener Ejektionsfraktion.

\begin{tabular}{|c|c|c|c|}
\hline Parameter & $\begin{array}{l}\text { Impaired LV ejection } \\
\text { fraction }(<55 \%)(n=30)\end{array}$ & $\begin{array}{l}\text { Preserved LV ejection fraction } \\
(\geq 55 \%)(n=39)\end{array}$ & $P$ value \\
\hline LV ejection fraction (\%) & $43.2 \pm 12.4$ & $61.5 \pm 4.7$ & $<0.001$ \\
\hline LV enddiastolic volume (ml) & $192.7 \pm 66.4$ & $148.0 \pm 27.9$ & 0.001 \\
\hline RV ejection fraction (\%) & $48.1 \pm 11.2$ & $58.8 \pm 5.8$ & $<0.001$ \\
\hline RV enddiastolic volume (ml) & $151.8 \pm 59.4$ & $121.8 \pm 31.8$ & 0.016 \\
\hline T2 SI ratio & $1.8 \pm 0.4$ & $2.0 \pm 0.4$ & 0.067 \\
\hline Early gadolinium enhancement ratio & $6.1 \pm 5.4$ & $3.2 \pm 2.1$ & 0.014 \\
\hline Late gadolinium enhancement (\%) & $5.3 \pm 4.4$ & $7.9 \pm 5.2$ & 0.036 \\
\hline Visible regional myocardial oedema & $23(77 \%)$ & $33(85 \%)$ & 0.701 \\
\hline Visible late gadolinium enhancement & $25(83 \%)$ & $36(92 \%)$ & 0.219 \\
\hline Positive Lake Louise criteria & $25(83 \%)$ & $32(82 \%)$ & 0.889 \\
\hline LV longitudinal strain (\%) & $-15.5 \pm 4.3$ & $-21.0 \pm 4.1$ & $<0.001$ \\
\hline LV longitudinal strain rate $(1 / \mathrm{s})$ & $-1.4 \pm 0.4$ & $-1.6 \pm 0.4$ & 0.006 \\
\hline LV circumferential strain (\%) & $-15.6 \pm 5.7$ & $-23.3 \pm 3.8$ & $<0.001$ \\
\hline LV circumferential strain rate $(1 / \mathrm{s})$ & $-1.4 \pm 0.4$ & $-1.8 \pm 0.5$ & $<0.001$ \\
\hline LV radial strain (\%) & $26.6 \pm 9.5$ & $39.6 \pm 11.9$ & $<0.001$ \\
\hline LV radial strain rate $(1 / \mathrm{s})$ & $1.9 \pm 0.5$ & $2.3 \pm 0.7$ & 0.006 \\
\hline RV longitudinal strain (\%) & $-20.4 \pm 5.5$ & $-24.7 \pm 5.8$ & 0.003 \\
\hline RV longitudinal strain rate $(1 / \mathrm{s})$ & $-1.8 \pm 0.5$ & $-2.00 \pm 0.6$ & 0.359 \\
\hline RV circumferential strain (\%) & $-11.7 \pm 3.3$ & $-15.1 \pm 3.1$ & $<0.001$ \\
\hline RV circumferential strain rate $(1 / \mathrm{s})$ & $-1.23 \pm 0.30$ & $-1.38 \pm 0.43$ & 0.100 \\
\hline RV systolic radial strain (\%) & $17.66 \pm 6.13$ & $20.88 \pm 7.33$ & 0.055 \\
\hline RV radial strain rate $(1 / \mathrm{s})$ & $1.39 \pm 0.35$ & $1.61 \pm 0.75$ & 0.116 \\
\hline
\end{tabular}

In this regard, it is also important to mention that myocardial strain analysis using the feature tracking technique can be performed using routinely acquired cine CMR images and without the need of additional contrast administration.

\section{Limitations}

Although endomyocardial biopsy is regarded as the reference standard for the diagnosis of myocarditis, it was not performed in this study. Instead, as reported previously in multiple CMR studies, the initial diagnosis of acute myocarditis was mainly made based on clinical parameters [6, 7]. Alterations of myocardial strain parameters are non-specific and can be detected in many acute and chronic cardiac diseases and conditions (e. g. in patients longstanding chronic disease [34] or significant coronary artery disease [35]). Due to the retrospective study design, patients were investigated at three different CMR scanners, which might have influenced some quantitative measurements (e.g. myocardial strain analysis). However, differences in the magnitude of longitudinal and circumferential strains at different field strengths have been reported to be rather small [36].

\section{Conclusions}

In patients with acute myocarditis, CMR strain analysis may be a new tool to monitor LV and RV functional impairment over the course of the disease. Furthermore, LV longitudinal strain has the potential to become a new CMR parameter for the independent prediction of functional recovery.

\section{Conflict of Interest}

The authors declare that they have no conflict of interest. 
- Table 4 Baseline CMR predictors of functional recovery upon follow-up for the whole study population $(n=69)$.

- Tab.4 Prädiktoren der Baseline-Untersuchung für eine Funktionsnormalisierung in der Nachuntersuchung für das gesamte Studienkollektiv $(\mathrm{n}=69)$.

\begin{tabular}{|c|c|c|c|c|}
\hline \multirow[b]{2}{*}{ Parameter } & \multicolumn{2}{|l|}{ Univariate } & \multicolumn{2}{|l|}{ Multivariate } \\
\hline & Odds ratio & $P$ value & Odds ratio & P value \\
\hline LV ejection fraction & $1.232(1.088-1.395)$ & 0.001 & - & - \\
\hline RV ejection fraction & $1.190(1.064-1.331)$ & 0.002 & - & - \\
\hline T2 SI ratio & $3.344(0.355-31.535)$ & 0.292 & - & - \\
\hline Early gadolinium enhancement ratio & $0.901(0.767-1.058)$ & 0.203 & - & - \\
\hline Late gadolinium enhancement (\%) & $1.109(0.917-1.343)$ & 0.286 & - & - \\
\hline Visible regional myocardial oedema & $5.778(1.219-27.388)$ & 0.027 & - & - \\
\hline Visible late gadolinium enhancement & $3.056(0.501-18.645)$ & 0.228 & - & - \\
\hline Positive Lake Louise criteria & $0.320(0.066-1.544)$ & 0.156 & - & - \\
\hline LV global peak systolic longitudinal strain & $0.303(0.128-0.718)$ & 0.007 & $0.303(0.128-0.718)$ & 0.007 \\
\hline LV global peak systolic circumferential strain & $0.494(0.295-0.826)$ & 0.007 & - & - \\
\hline LV global peak systolic radial strain & $1.227(1.078-1.397)$ & 0.002 & - & - \\
\hline RV global peak systolic longitudinal strain & $0.702(0.563-0.877)$ & 0.002 & - & - \\
\hline RV global peak systolic circumferential strain & $0.737(0.584-0.929)$ & 0.010 & - & - \\
\hline RV global peak systolic radial strain & $1.353(1.093-1675)$ & 0.006 & - & - \\
\hline \multicolumn{5}{|c|}{$\begin{array}{l}\text { CMR = cardiac magnetic resonance, } \mathrm{LV}=\text { left ventricular, } \mathrm{RV}=\text { right ventricular. Predictors of functional recovery upon follow-up were determined by using } \\
\text { binary logistic regression analysis. Significant univariate predictors were entered into the multivariate model. Odds ratios are given with } 95 \% \text { confidence } \\
\text { interval. }\end{array}$} \\
\hline
\end{tabular}

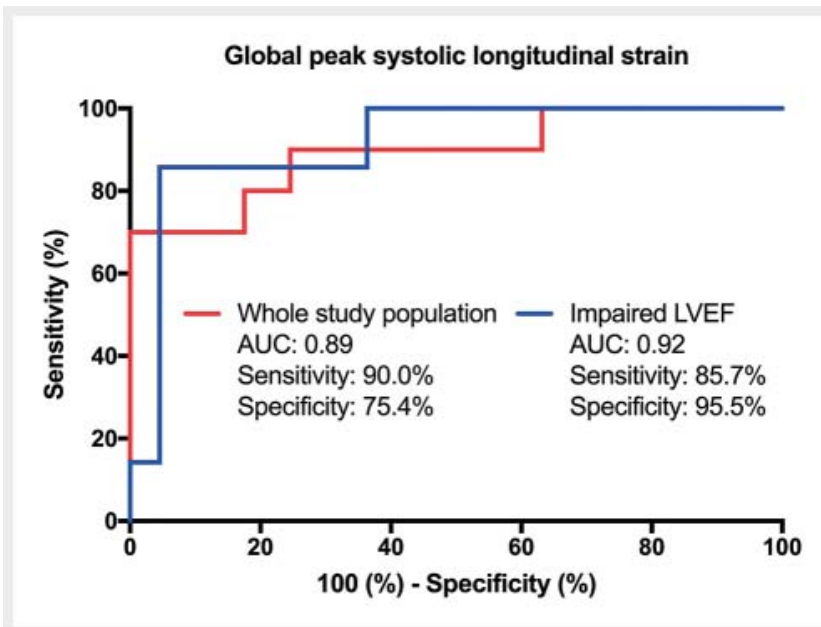

- Fig. 5 Receiver operating characteristic (ROC) curves for left ventricular longitudinal strain for the prediction of functional recovery. ROC curves are given for the whole study population $(n=69)$ and for patients with initially impaired left ventricular ejection fraction (LVEF) $(n=30)$.

- Abb.5 Receiver-Operating-Characteristic-Kurven (ROC-Kurven) des linksventrikulären, longitudinalen Strains für die Prädiktion einer Funktionsnormalisierung. Es werden ROC-Kurven für die gesamte Studienpopulation und für Patienten mit initital eingeschränkter linksventrikulärer Ejektionsfraktion (LVEF) gezeigt.

\section{Widmung}

Diese Arbeit ist Herrn Professor Hans H. Schild gewidmet, bei dem wir uns herzlich für die langjährige und stete Unterstützung in allen klinischen und wissenschaftlichen Belangen bedanken möchten.

References

[1] Drory $Y$, Turetz $Y$, Hiss $Y$ et al. Sudden unexpected death in persons less than 40 years of age. The American journal of cardiology 1991; 68: $1388-1392$

[2] Pollack A, Kontorovich AR, Fuster V et al. Viral myocarditis-diagnosis, treatment options, and current controversies. Nature reviews Cardiology 2015. doi:10.1038/nrcardio.2015.108

[3] Maron BJ, Udelson JE, Bonow RO et al. Eligibility and Disqualification Recommendations for Competitive Athletes With Cardiovascular Abnormalities: Task Force 3: Hypertrophic Cardiomyopathy, Arrhythmogenic Right Ventricular Cardiomyopathy and Other Cardiomyopathies, and Myocarditis: A Scientific Statement From the American Heart Association and American College of Cardiology. Journal of the American College of Cardiology 2015; 66: 2362-2371. doi:10.1016/j. jacc.2015.09.035

[4] Liu PP, Mason JW. Advances in the understanding of myocarditis. Circulation 2001; 104: 1076-1082

[5] Caforio AL, Pankuweit S, Arbustini E et al. Current state of knowledge on aetiology, diagnosis, management, and therapy of myocarditis: a position statement of the European Society of Cardiology Working Group on 
- Table 5 Baseline CMR predictors of functional recovery in patients with impaired LV ejection fraction $(<55 \%)(n=30)$.

- Tab.5 Prädiktoren der Baseline-Untersuchung für eine Funktionsnormalisierung in der Nachuntersuchung bei Patienten mit initial reduzierter linksventrikulärer Funktion $(<55 \%)(n=30)$.

\begin{tabular}{|c|c|c|c|c|}
\hline \multirow[b]{2}{*}{ Parameter } & \multicolumn{2}{|l|}{ Univariate } & \multicolumn{2}{|l|}{ Multivariate } \\
\hline & Odds ratio & $P$ value & Odds ratio & P value \\
\hline LV ejection fraction & $1.206(1.059-1.374)$ & 0.005 & - & - \\
\hline RV ejection fraction & $1.129(1.011-1.262)$ & 0.032 & - & - \\
\hline T2 SI ratio & $1.467(0.142-15.190)$ & 0.748 & - & - \\
\hline Early gadolinium enhancement ratio & $0.969(0.816-1.150)$ & 0.719 & - & - \\
\hline Late gadolinium enhancement (\%) & $1.026(0.846-1.246)$ & 0.791 & - & - \\
\hline Visible regional myocardial oedema & $6.333(1.001-40.071)$ & 0.050 & - & - \\
\hline Visible late gadolinium enhancement & $2.111(0.283-15.770)$ & 0.466 & - & - \\
\hline Positive Lake Louise criteria & $0.167(0.022-1.282)$ & 0.085 & - & - \\
\hline LV global peak systolic longitudinal strain & $0.296(0.102-0.858)$ & 0.025 & $0.296(0.102-0.858)$ & 0.025 \\
\hline LV global peak systolic circumferential strain & $0.523(0.313-0.875)$ & 0.013 & - & - \\
\hline LV global peak systolic radial strain & $1.202(1.04-1.382)$ & 0.010 & - & - \\
\hline RV global peak systolic longitudinal strain & $0.665(0.582-0.9199$ & 0.013 & - & - \\
\hline RV global peak systolic circumferential strain & $0.835(0.642-1.084)$ & 0.176 & - & - \\
\hline RV global peak systolic radial strain & $1.327(1.054-1.671)$ & 0.016 & - & - \\
\hline
\end{tabular}

Myocardial and Pericardial Diseases. European heart journal 2013; 34: 2648a-2648d. doi:10.1093/eurheartj/eht210

[6] Luetkens JA, Homsi R, Sprinkart AM et al. Incremental value of quantitative CMR including parametric mapping for the diagnosis of acute myocarditis. Eur Heart J Cardiovasc Imaging 2016; 17: 154-161. doi:10.1093/ehjci/jev246

[7] Luetkens JA, Doerner J, Thomas DK et al. Acute Myocarditis: Multiparametric Cardiac MR Imaging. Radiology 2014; 273: 383-392. doi:10.1148/radiol.14132540

[8] Luetkens JA, Homsi R, Dabir D et al. Comprehensive Cardiac Magnetic Resonance for Short-Term Follow-Up in Acute Myocarditis. J Am Heart Assoc 2016: 5. doi:10.1161/JAHA.116.003603

[9] Vermes E, Childs H, Faris P et al. Predictive value of CMR criteria for LV functional improvement in patients with acute myocarditis. Eur Heart J Cardiovasc Imaging 2014; 15: 1140 - 1144. doi:10.1093/ehjci/jeu099

[10] Grün S, Schumm J, Greulich S et al. Long-Term Follow-Up of BiopsyProven Viral MyocarditisPredictors of Mortality and Incomplete Recovery. Journal of the American College of Cardiology 2012; 59: 1604 1615. doi:10.1016/j.jacc.2012.01.007

[11] Weigand J, Nielsen JC, Sengupta PP et al. Feature Tracking-Derived Peak Systolic Strain Compared to Late Gadolinium Enhancement in TroponinPositive Myocarditis: A Case-Control Study. Pediatr Cardiol 2015. doi:10.1007/s00246-015-1333-z

[12] Baessler B, Schaarschmidt F, Dick A et al. Diagnostic implications of magnetic resonance feature tracking derived myocardial strain parameters in acute myocarditis. European journal of radiology 2016; 85: 218 - 227. doi:10.1016/j.ejrad.2015.11.023

[13] Luetkens JA, Schlesinger-Irsch U, Kuetting DL et al. Feature-tracking myocardial strain analysis in acute myocarditis: diagnostic value and association with myocardial oedema. Eur Radiol 2017. doi:10.1007/ s00330-017-4854-4

[14] Mendes LA, Dec GW, Picard MH et al. Right ventricular dysfunction: an independent predictor of adverse outcome in patients with myocarditis. American heart journal 1994; 128: $301-307$

[15] Friedrich MG, Sechtem U, Schulz-Menger J et al. Cardiovascular magnetic resonance in myocarditis: A JACC White Paper. Journal of the American College of Cardiology 2009; 53: 1475 - 1487. doi:10.1016/j. jacc.2009.02.007

[16] Schulz-Menger J, Bluemke DA, Bremerich J et al. Standardized image interpretation and post processing in cardiovascular magnetic resonance: Society for Cardiovascular Magnetic Resonance (SCMR) board of trustees task force on standardized post processing. Journal of cardiovascular magnetic resonance : official journal of the Society for Cardiovascular Magnetic Resonance 2013; 15: 35. doi:10.1186/1532-429X-1535

[17] Mavrogeni S, Spargias C, Bratis C et al. Myocarditis as a precipitating factor for heart failure: evaluation and 1-year follow-up using cardiovascular magnetic resonance and endomyocardial biopsy. Eur J Heart Fail 2011; 13: 830-837. doi:10.1093/eurjhf/hfr052

[18] Wagner A, Schulz-Menger ], Dietz R et al. Long-term follow-up of patients paragraph sign with acute myocarditis by magnetic paragraph sign resonance imaging. MAGMA 2003; 16: 17-20. doi:10.1007| s10334-003-0007-7

[19] Ferreira VM, Piechnik SK, Dall'Armellina E et al. Non-contrast T1-mapping detects acute myocardial edema with high diagnostic accuracy: a comparison to T2-weighted cardiovascular magnetic resonance. Journal of cardiovascular magnetic resonance : official journal of the Society for 
Cardiovascular Magnetic Resonance 2012; 14: 42. doi:10.1186/1532429X-14-42

[20] Monney PA, Sekhri N, Burchell T et al. Acute myocarditis presenting as acute coronary syndrome: role of early cardiac magnetic resonance in its diagnosis. Heart 2011; 97: 1312 - 1318. doi:10.1136/hrt.2010.204818

[21] Kidambi A, Mather AN, Swoboda P et al. Relationship between myocardial edema and regional myocardial function after reperfused acute myocardial infarction: an MR imaging study. Radiology 2013; 267: 701 708. doi:10.1148/radiol.12121516

[22] Zagrosek A, Abdel-Aty H, Boye P et al. Cardiac magnetic resonance monitors reversible and irreversible myocardial injury in myocarditis. JACC Cardiovascular imaging 2009; 2: 131 -138. doi:10.1016/j. jcmg.2008.09.014

[23] Bohnen S, Radunski UK, Lund GK et al. Tissue characterization by T1 and T2 mapping cardiovascular magnetic resonance imaging to monitor myocardial inflammation in healing myocarditis. Eur Heart J Cardiovasc Imaging 2017; 18: 744 - 751. doi:10.1093/ehjci/jex007

[24] Di Marco A, Anguera I, Schmitt M et al. Late Gadolinium Enhancement and the Risk for Ventricular Arrhythmias or Sudden Death in Dilated Cardiomyopathy: Systematic Review and Meta-Analysis. JACC Heart Fail 2017; 5: 28 -38. doi:10.1016/j.jchf.2016.09.017

[25] Stiermaier T, Fohrenbach F, Klingel K et al. Biventricular endomyocardial biopsy in patients with suspected myocarditis: Feasibility, complication rate and additional diagnostic value. International journal of cardiology 2017; 230: 364 - 370. doi:10.1016/j.ijcard.2016.12.103

[26] Lee JW, Jeong Y], Lee G et al. Predictive Value of Cardiac Magnetic Resonance Imaging-Derived Myocardial Strain for Poor Outcomes in Patients with Acute Myocarditis. Korean journal of radiology : official journal of the Korean Radiological Society 2017; 18: 643 - 654. doi:10.3348/ kjr.2017.18.4.643

[27] Kalam K, Otahal P, Marwick TH. Prognostic implications of global LV dysfunction: a systematic review and meta-analysis of global longitudinal strain and ejection fraction. Heart 2014; 100: 1673-1680. doi:10.1136/ heartjnl-2014-305538

[28] Arenja N, Riffel JH, Fritz T et al. Diagnostic and Prognostic Value of LongAxis Strain and Myocardial Contraction Fraction Using Standard Cardio- vascular MR Imaging in Patients with Nonischemic Dilated Cardiomyopathies. Radiology 2017; 283: 681 -691. doi:10.1148/radiol.2016161184

[29] Arenja N, Riffel JH, Halder M et al. The prognostic value of right ventricular long axis strain in non-ischaemic dilated cardiomyopathies using standard cardiac magnetic resonance imaging. Eur Radiol 2017; 27 : 3913 - 3923. doi:10.1007/s00330-016-4729-0

[30] Buss S], Breuninger K, Lehrke S et al. Assessment of myocardial deformation with cardiac magnetic resonance strain imaging improves risk stratification in patients with dilated cardiomyopathy. Eur Heart J Cardiovasc Imaging 2015; 16: 307 - 315. doi:10.1093/ehjci/jeu181

[31] Andre F, Steen H, Matheis P et al. Age- and gender-related normal left ventricular deformation assessed by cardiovascular magnetic resonance feature tracking. Journal of Cardiovascular Magnetic Resonance 2015; 17: 25

[32] Taylor RJ, Moody WE, Umar F et al. Myocardial strain measurement with feature-tracking cardiovascular magnetic resonance: normal values. Eur Heart J Cardiovasc Imaging 2015; 16: 871 - 881. doi:10.1093/ehjci/ jev006

[33] Hsiao JF, Koshino Y, Bonnichsen CR et al. Speckle tracking echocardiography in acute myocarditis. The international journal of cardiovascular imaging 2013; 29: 275-284. doi:10.1007/s10554-012-0085-6

[34] Luetkens JA, Doerner J, Schwarze-Zander C et al. Cardiac Magnetic Resonance Reveals Signs of Subclinical Myocardial Inflammation in Asymptomatic HIV-Infected Patients. Circulation Cardiovascular imaging 2016; 9: e004091. doi:10.1161/CIRCIMAGING.115.004091

[35] Sarvari SI, Haugaa KH, Zahid W et al. Layer-specific quantification of myocardial deformation by strain echocardiography may reveal significant CAD in patients with non-ST-segment elevation acute coronary syndrome. JACC Cardiovascular imaging 2013; 6: 535- 544. doi:10.1016/j.jcmg.2013.01.009

[36] Mangion K, Clerfond G, McComb C et al. Myocardial strain in healthy adults across a broad age range as revealed by cardiac magnetic resonance imaging at 1.5 and 3.0T: Associations of myocardial strain with myocardial region, age, and sex. J Magn Reson Imaging 2016; 44: 1197 1205. doi:10.1002/jmri.25280 